\title{
Novedades jurisprudenciales en materia de transmisión de empresa: la labor del TJUE y del TS en los últimos dos años
}

\section{The recent case law on transfer of undertaking: CJEU and TS's answers within the last two years}

\author{
Luis Enrique Nores Torres \\ Profesor Titular Derecho del Trabajo y Seguridad Social \\ Universitat de València
}

ORCID ID: 0000-0001-6128-8552

Recibido: $31 / 7 / 19$

Aceptado: 29/10/19

doi: https://doi.org/10.20318/labos.2020.5301
Resumen: Una institución que ha originado una notable atención en los últimos años es la de la transmisión de empresa. En efecto, aún tratándose de un tema "tradi- cional" en el Derecho del Trabajo, asistimos a una especie de "interés renovado" por el mismo que seguramente derive de los pronunciamientos judiciales dic- tados en la materia y que han aportado nuevas perspectivas de análisis, tanto desde una óptica general, como desde otra más específica. El objeto de este trabajo se dirige a dar cuenta de las principales "novedades jurisprudenciales" habidas en este terreno.

Palabras clave: Transmisión de empresa, subrogación, responsabilidad solidaria, prescripción.

Abstract: An item that has caused considerable attention in recent years is that of transfers of undertakings. Indeed, even in the case of a "traditional" theme in Labor Law, we are witnessing a kind of "renewed interest" for the same that it is surely derived from the judicial pronouncements dictated in the matter and that have contributed new perspectives of analysis, both from an optics general, as from another more specific. The purpose of this work is to give notice of the main recent case law in this field.

Keywords: $\quad$ Transfer of undertaking, subrogation, jointly and several liability, terms.

\section{Introducción}

1. Una institución que ha originado una notable atención en los últimos años es, sin lugar a dudas, la de la transmisión de empresa. En efecto, aún tratándose de un tema "tradicional" en el Derecho del Trabajo, asistimos a una especie de "interés renovado" por el mismo que seguramente derive de los pronunciamientos judiciales dictados en la materia y que han aportado nuevas pers-

*lenores@uv.es 
pectivas de análisis, tanto desde una óptica general, como desde otra más específica. Así, por ejemplo, las cuestiones relacionadas con la consideración de la sucesión de contratas como un fenómeno de transmisión sujeto a la disciplina del art. 44 ET, el alcance y efectos de las llamadas subrogaciones convencionales o la problemática de las reversiones de contratas en el sector público. Pues bien, precisamente, el objeto de este trabajo se dirige a dar cuenta de las principales "novedades jurisprudenciales" habidas en este terreno.

1.1. Y ahí surge el primer problema, ya que el diccionario de la Real Academia Española proporciona hasta siete acepciones de lo que pueda entenderse como tal; y aunque, a mi juicio, la más sugerente sea la séptima ("extrañeza o admiración que causa lo antes no visto ni oído"), creo que debemos movernos en la intersección entre la cuarta ("cambio producido en algo") y la quinta ("suceso reciente del que se da noticia"). Pues bien, desde esa perspectiva, me ha parecido que debía centrarme en los pronunciamientos jurisprudenciales "recientes", entendiendo por tales (otra vez según la RAE), aquellos, "nuevos, frescos o acabados de hacer" o, mejor aún, "que han sucedido hace poco". En este sentido, he tomado como referente los dos últimos años (2018 y 2019), efectuando una batida en los repertorios jurisprudenciales al uso buscando las sentencias emanadas del TJUE y del TS a lo largo de dicho período en la materia seńalada. El resultado no es espectacular: en el caso del TJUE, las sentencias relevantes en esta materia desde la perspectiva "social" no alcanzan la docena; por lo que respecta a las procedentes del TS, el número supera el medio centenar, si bien en muchos casos son de carácter reiterativo.

1.2. A partir de esta labor, no he querido configurar la exposición analizando cada uno de estos pronunciamientos por orden cronológico, dando cuenta de los hechos litigiosos de cada supuesto, la cuestión objeto del debate y la respuesta proporcionada por los órganos judiciales; tampoco, me ha parecido conveniente efectuar un repaso de toda la institución adornándolo con estas novedades, sino que mi objetivo ha sido tratar de sistematizar ese conjunto de sentencias por bloques temáticos, esto es, ordenarlas atendiendo a las cuestiones abordadas, de manera que ello permita hacernos una idea de en qué cuestiones se centra el debate jurídico y qué soluciones se están dando, con independencia de que tales soluciones no siempre constituyan un verdadero cambio o novedad.

2. Así las cosas, la pregunta que surge de manera inmediata es la relativa a cuáles son esas cuestiones. A mi juicio, yo creo que cabe diferenciar cinco grandes bloques de materias ${ }^{1}$.

2.1. De entrada, hay un conjunto de pronunciamientos relevantes que se relacionan todos ellos con el presupuesto aplicativo, ya sea desde la perspectiva de que aportan datos de interés sobre cómo interpretar los requisitos tradicionales para entender que se ha producido una transmisión, ya porque resuelven supuestos específicos.

2.2. En segundo lugar, debe llamarse la atención sobre aquellas sentencias que abordan los efectos de la subrogación convencional, en concreto, en lo relativo a la responsabilidad solidaria, donde llama la atención el giro producido en una línea jurisprudencial muy asentada en la materia a raíz de la STJUE de 11 de julio de 2018 (asunto C-60/17, Somoza Hermo), un cambio que merece la pena analizar por la polémica que ha levantado.

\footnotetext{
${ }^{1}$ La jurisprudencia en la materia proporciona otros puntos para la reflexión, como evidencia el reciente estudio colectivo dirigido por el profesor García Murcia: GARCÍA MURCIA, J. (Dir.), Transmisión de empresa y sucesión en el desarrollo de actividades empresariales. Un estudio a partir de la jurisprudencia del Tribunal Supremo, Cizur Menor, Thomson Reuters Aranzadi, 2019.
} 
2.3. La responsabilidad solidaria, en el texto estatutario, queda sujeta a un específico plazo de tres ańos. Pues bien, también en este terreno ha incidido la labor jurisprudencial, consolidándose una tendencia anunciada en pronunciamientos dictados con anterioridad en el ámbito de la responsabilidad en materia de contratas y subcontratas. A esta cuestión me referiré en tercer lugar.

2.4. Sin abandonar este terreno de los efectos, un cuarto bloque de pronunciamientos se centran en la otra consecuencia esencial, la subrogación del cesionario en las relaciones laborales del cedente, en concreto, en los supuestos de sucesión de contratas cuando se produce una reducción de la misma, una materia en la que también se han dejado sentir los efectos del asunto Somoza Hermo.

2.5. En fin, el último bloque de pronunciamientos abordan la relación transmisión-concurso, resolviendo una cuestión muy concreta: el orden jurisdiccional competente para determinar si existe o no transmisión, así como la fijación de la responsabilidad por las deudas nacidas con anterioridad a la adjudicación de la unidad productiva respecto relaciones que además ya se extinguieron.

\section{El presupuesto aplicativo}

3. Tal y como he anunciado, hay un primer grupo de pronunciamientos que se relacionan todos ellos con el presupuesto aplicativo del art. 44 ET. Este presupuesto, como es sabido, se articula sobre la concurrencia de dos requisitos básicos ${ }^{2}$. En primer lugar, un requisito que se suele denominar subjetivo, consistente en la existencia de un cambio en la titularidad de la empresa, centro de trabajo o unidad productiva autónoma. En segundo lugar, se necesita otro requisito de carácter objetivo, pues se relaciona con el objeto de la transmisión; así, la transmisión debe afectar a un conjunto organizado de bienes que sean aptos para llevar a cabo una explotación o, en los términos legales, una entidad económica que mantenga su identidad, entendida como conjunto de medios organizados a fin de llevar a cabo una actividad económica, accesoria o esencial.

4. Al hilo de estos requisitos, se ha ido elaborando una rica jurisprudencia llena de matices que configura lo que podríamos denominar como construcción clásica sobre cuándo puede entenderse que ha habido transmisión. Pues bien, nada de esta construcción clásica se ha visto alterado por la jurisprudencia más reciente, aunque, como anticipaba, resulta posible encontrar algunas sentencias de interés bien porque aportan matices sobre cómo interpretar los requisitos tradicionales para entender que se ha producido una transmisión, bien porque resuelven supuestos específicos.

4.1. En el primer sentido, los pronunciamientos que deben ser reseñados son muy variopintos, como diversos son también los aspectos en los que tales resoluciones inciden:

\footnotetext{
${ }^{2}$ Entre otros, GONZÁLEZ BIEDMA. E., "Los efectos jurídico-laborales de la sustitución de empresas contratistas de servicios", Relaciones Laborales-II, 1993, p. 343; LLANO SÁNCHEZ, M., Responsabilidad empresarial en las contratas y subcontratas, Madrid, La Ley, 1999, p. 146; GARCÍA ORTEGA, J., "La sucesión de contratistas", en BLAT GIMENO, F. et altri, Descentralización productiva y protección del trabajo en contratas. Estudios en recuerdo de Francisco Blat Gimeno, Valencia, Tirant lo Blanch, 2000, p. 343; SALA FRANCO, T., "La sucesión de contratas", en PEDRAJAS MORENO, A. (Dir.), La externalización de actividades laborales (outsourcing): una visión multidisciplinar, Valladolid, Lex Nova, 2002, p. 268; MORENO GENÉ, J., El nuevo régimen jurídico-laboral de la transmisión de empresa, Valencia, Tirant lo Blanch, 2003, p. 25; MONTOYA MEDINA, D., Trabajo en contratas y protección de los trabajadores, Valencia, Tirant lo Blanch, 2004, p. 394; SALA FRANCO, T.; PEDRAJAS MORENO, A., "Los problemas laborales de la sucesión de contratas", en BLASCO PELLICER, A. (Coord.), El empresario laboral. Estudios jurídicos en homenaje al profesor Camps Ruiz con motivo de su jubilación, Valencia, Tirant lo Blanch, 2010, p. 389.
} 
a) Así, de entrada, por lo que respecta al requisito subjetivo - esto es, el cambio en la titularidad de la empresa, centro de trabajo o unidad productiva-, hay que recordar la variedad de negocios jurídicos a través de los cuales se puede producir. En este sentido, debe recordarse que si bien las primeras interpretaciones se movieron en la línea de entender que ese cambio debía derivar de un negocio jurídico directo entre cedente y cesionario, la evolución posterior llevó a admitir que el requisito también se entienda satisfecho en los casos en que la alteración resulta de un negocio indirecto o con intervención de terceros ${ }^{3}$. Y entre tales negocios se encuentra la fusión por absorción, como expresamente recoge el art. 44.8.II ET.

A ello se refiere la STS de 30 de enero de 2018, rec. 9/2017, al resolver un supuesto en el que curiosamente era la representación de los trabajadores la que negaba la existencia de transmisión, afirmando que se trataba de una mera estrategia diseńada desde la empresa matriz para evitar la aplicación de un determinado convenio colectivo en una de las empresas del grupo, en concreto, el convenio colectivo de la industria química, y acogerse a otro diverso, el convenio colectivo de recuperación y reciclado de residuos.

Sin embargo, el TS recuerda la claridad del art. 44 ET, así como que no nos encontramos ante un mero cambio de denominación societaria, sino ante una verdadera sucesión, cuya legalidad no se ha cuestionado, ni siquiera por la vía del fraude o el abuso de derecho. En definitiva, la fusión podrá ser un presupuesto aplicativo del art. $44 \mathrm{ET}$, salvo que se haya usado de forma abusiva o fraudulenta la figura, algo que en el supuesto de hecho no constaba que se hubiera producido: por un lado, la absorción no se circunscribía a la empresa que daba empleo a los afectados, sino que alcanzaba a otras del grupo; por otro lado, constaba en la documentación aportada en juicio todo un conjunto de motivos racionales para llevarla a cabo, como, por ejemplo, el evitar duplicidades.

b) Por lo que respecta al elemento objetivo -esto es, el objeto de la transmisión-, ya sabemos que su concurrencia se aprecia procediendo a una valoración de conjunto sobre una pluralidad de elementos concurrentes, no solo de carácter material, sino entendidos en un sentido amplio, tal como indicó en su momento el TJUE en el asunto Spijkers ${ }^{4}$ y que después han seguido otros muchos pronunciamientos 5 .

En efecto, la jurisprudencia comunitaria indica que, entre los múltiples aspectos que el juez nacional debe valorar, se encontraría el tipo de empresa o centro de actividad de que se trate; el hecho de que haya habido o no una transmisión de los activos materiales, como edificios e inmuebles, así como el valor de los inmateriales en el momento de la transmisión; el hecho de que se haya transmitido o no la clientela; el grado de analogía entre las actividades anteriores y posteriores a la transmisión; la duración de la suspensión de la actividad; así como también el hecho de que el empresario nuevo se haga cargo o no de la mayoría de los trabajadores del predecesor. Por otra parte, algunos pronunciamientos posteriores han señalado que además de la actividad deben valorarse otros elementos como el personal que la integra, el marco de actuación, la organización del trabajo, sus métodos de explotación o, en su caso, los medios de explotación ${ }^{6}$, a lo que se ha ańadido la organización, el funcionamiento, la financiación, la gestión y las normas jurídicas aplicables ${ }^{7}$.

\footnotetext{
${ }^{3}$ STJUE de 19 mayo 1992 (asunto C-29/91, Redmond-Stichting).

${ }^{4}$ STJUE de 18 de marzo de 1986 (asunto C-24/85, Spijkers).

${ }^{5}$ SsTJUE de 19 de mayo de 1992 (asunto C-29/91, Redmond-Stichting); de 12 de noviembre de 1992 (asunto C-209/91, Watson Rask;) de 14 de abril de 1994 (asunto C-392/92, Schmidt); de 7 de marzo de 1996, asuntos C-171/94 y 172/94, Merckx y Neuhuys); de 10 de diciembre de 1998 (asuntos C-127/96, C-229/96 y C-74/97, Hernández Vidal y otros); de 10 de diciembre de 1998 (asuntos C-173/96 y 247/96, Sánchez Hidalgo y otros); de 2 de diciembre de 1999 (asunto C-234/98, Allen); de 26 de septiembre de 2000 (asunto C-175/99, Didier Mayeur); de 25 de enero de 2001 (asunto C-172/99, Oy Liikenne); de 24 de enero de 2002 (asunto C-51/00, Temco); de 20 de noviembre de 2003 (asunto C-340/01, Abler); de 15 de diciembre de 2005 (asuntos 232/04 y 233/04, Nurten Güney-Görres); de 29 de julio de 2010 (asunto C-151/09, FSP/UGT/Ayuntamiento La Linea); de 20 de enero de 2011 (asunto C-463/09, Martín Valor).

${ }^{6}$ STJUE de 11 de marzo de 1997 (asunto C-13/95, Süzen).

${ }^{7}$ SsTSJ de 26 de septiembre de 2000 (asunto C-175/99, Didier Mayeur) y de 25 de enero de 2001 (asunto C-172/99, Oy Liikenne).
} 
Ello es así en general, ya que debe recordarse cómo el TJUE matizó esta doctrina para aquellos sectores productivos y actividades que descansan fundamentalmente en la mano de obra y que no requieren de un importante soporte patrimonial para su funcionamiento, donde, en consecuencia, no resultaría procedente exigir su transmisión. Y es que, en estos casos, la contratación de una parte importante de los efectivos personales del antecesor en número y competencias será el criterio determinante para determinar si existe o no transmisión ${ }^{8}$. Este criterio, forjado por la jurisprudencia comunitaria, se conoce como "criterio de la sucesión de plantilla", y, a pesar de las reticencias iniciales a su incorporación en el ámbito interno por parte del TS, al final acabó por asumirse en un par de sentencias dictadas en el año 2004 resolviendo dos asuntos tan diversos como fueron el del handling de Iberia ${ }^{9}$ y el de una contrata del servicio de mantenimiento de unas instalaciones deportivas ${ }^{10}$. Con posterioridad, el criterio de la asunción de plantilla fue invocado en otros pronunciamientos relacionados con la gestión de un aparcamiento público ${ }^{11}$, con el servicio de mantenimiento eléctrico de una empresa de hidrocarburos ${ }^{12}$ o con una contrata de limpieza ${ }^{13}$.

Pues bien, en ambos terrenos -es decir, tanto en el de la sucesión de contratas "materializadas", como en el de aquellas otras "desmaterializadas" a las que se aplica el criterio antedicho de la sucesión de plantilla- puede destacarse la existencia de diversos pronunciamientos de interés dentro del período analizado.

— En efecto, en el primero de ellos, aunque la aportación de los elementos materiales para llevar a cabo la explotación es muy relevante en los supuestos de transmisión ligados a los fenómenos de sucesión de contratas materializadas, el hecho de que sean proporcionados por el nuevo contratista o concesionario no excluye que se afirme la existencia de una transmisión siempre que pueda entenderse que, en el fondo, es el sujeto descentralizador quien los sufraga o proporciona. El ejemplo lo brinda la STS de 17 de enero de 2018, rec. 171/2017.

$\mathrm{El}$ asunto resuelto por esta sentencia gira en torno al servicio de restauración licitado por el Real Club Náutico de Gran Canaria (RCNGC). Esta entidad había suscrito un arrendamiento de industria con una determinada empresa, cediéndole el espacio para su prestación y proporcionado todos los medios necesarios para el desarrollo. Al no renovarse el contrato, el RCNGC, en principio, se plantea continuar por sí mismo la actividad, si bien finalmente encuentra un nuevo arrendatario que debería aportar los elementos necesarios para la explotación, lo que debería determinar que se excluyese la existencia de transmisión en aplicación de las reglas generales.

Sin embargo, el TS parte de la base de que el RCNGC arrienda la explotación de una industria a través de un negocio jurídico suscrito primero con la saliente y después con la entrante, por medio del cual aporta una pluralidad de elementos que permiten llevar a cabo la explotación, algo que es constitutivo de una transmisión. A partir de ahí subraya que el hecho de que la nueva concesionaria del servicio compre maquinaria no desvirtúa tal idea, pues, al margen de que no constaba cuál era dicha maquinaria, existía una cláusula contractual por la que las nuevas máquinas las pagaba realmente el RCNCG, limitándose el concesionario a anticipar su pago. En definitiva, no puede

${ }^{8}$ SsTJUE de 11 de marzo de 1997 (asunto C-13/95, Süzen); de 10 de diciembre de 1998 (asuntos C-127/96, C-229/96 y C-74/97, Hernández Vidaly otros); de 10 de diciembre de 1998 (asuntos C-173/96 y 247/96, Sánchez Hidalgo y otros); de 24 de enero de 2002 (asunto C-51/00, Temco); de 13 de septiembre de 2007 (asunto C-485/05, Mohamed Jouini); de 29 de julio de 2010 (asunto C-151/09, FSP/UGT/Ayuntamiento La Linea); de 20 de enero de 2011 (asunto C-463/09, Martín Valor).

${ }^{9}$ STS de 21 de octubre de 2004, rec. 5075/2003, si bien en el caso no la aplica por tratarse de una asunción de plantilla no pacífica.

${ }^{10}$ STS de 27 de octubre de 2004, rec. 899/2002.

${ }^{11}$ STS de 4 de abril de 2005, rec. 2423/2003, si bien no se aplica porque no constaba que la empresa adjudicataria se hubiera quedado con parte sustancial de la plantilla.

${ }^{12}$ STS de 27 de junio de 2008, rec. 4773/2006, si bien tampoco en este caso se llega a aplicar porque la empresa no había contratado a nadie al reasumir la actividad.

${ }^{13}$ STS de 12 de julio de 2010, rec. 2300/2009. 
entenderse que el nuevo concesionario esté aportando los elementos necesarios para la ejecución de la actividad, por lo que la existencia de transmisión resulta clara.

- Por otra parte, también es posible encontrar pronunciamientos de interés en relación con la aplicación al caso concreto del criterio de asunción de la plantilla. El espacio de actuación de este criterio, como se ha recordado, se circunscribe en principio al de la sucesión en actividades desmaterializadas que descansan fundamentalmente en la mano de obra e implica que la contratación en número y competencias de una parte importante de la misma conduce a entender que se ha producido una transmisión.

Una primera sentencia que debe destacarse en este punto es la STS de 26 de octubre de 2018, rec. 2118/2016, ya que ayuda a comprender qué debemos considerar por actividades que descansan fundamentalmente en la mano de obra. El asunto controvertido era el siguiente: una determinada empresa suscribe un contrato de arrendamiento de servicios relativos a ciertas actividades submarinas relacionadas con el amarre y descarga de petroleros en una monoboya de una refinería, así como de control y mantenimiento. A pesar de que se contrató a cuatro buzos, un administrativo y un marinero de la empresa saliente, en sede judicial no se entendió que se debiese aplicar el criterio de sucesión de plantilla. Y es que si bien las labores de los buzos son cualitativamente muy relevantes, no puede entenderse que la actividad contratada descanse primordialmente en ellos, por lo tanto el hecho de su contratación constituye un criterio más a tener en cuenta a la hora de valorar la existencia de transmisión, pero no determina por sí solo la existencia de la misma. A partir de ahí, como la contratista entrante debía aportar una pluralidad de elementos patrimoniales de relevancia (embarcaciones, equipos de buceo, medios de seńalización, balizamiento, etc.) se negó acertadamente la existencia de transmisión.

Otra sentencia de interés que debe destacarse al hilo del criterio de la asunción de plantilla es la STS 22 de enero de 2019, rec. 3975/2016. Este pronunciamiento trae causa de un complejo asunto relacionado con la labor desarrollada por ciertos veterinarios al servicio de la Xunta de Galicia, inicialmente, como "pseuoautónomos" con una más que probable cesión ilegal, luego a través de dos empresas públicas sucesivas: primero TRAGSEGA, después SEAGA. Al extinguir esta última todas las relaciones laborales de los trabajadores a su servicio en el marco de un ERE tramitado en 2010, se plantea la cuestión de la transmisión desde la perspectiva de la antigüedad computable para calcular la indemnización por despido.

El TS tras recordar los múltiples conflictos que se han originado en relación con estas empresas, desde perspectivas muy distintas, y resaltar la dificultad que ello origina a efectos de la "contradicción" (véase al respecto, por ejemplo, la STS de 10 de abril de 2018, rec. 2287/2015), entra en el fondo del asunto y entiende que en este caso había transmisión por aplicación del criterio de asunción de la plantilla. La enseñanza más relevante que podemos extraer de esta sentencia es la relativa a que este criterio -el de asunción de plantilla- se afirma incluso cuando la mano de obra contratada por el sucesor lo ha sido en virtud de un concurso público superado por los afectados, algo que resulta criticable. Y es que ello se entendería en el supuesto de que esa asunción se hubiese producido de manera voluntaria -algo que, por lo demás, vedaría de forma clara la Ley 9/2017, de 98 de noviembre de Contratos del Sector Público (LCSP) en su art. 308 ${ }^{14}$-, o derivara de un convenio colectivo que resultase aplicable, pero no cuando se produce con ocasión de haber superado los candidatos un concurso público; otra cosa habría sido que en ese concurso se hubiese tenido

\footnotetext{
${ }^{14}$ GOERLICH PESET, J. Ma; NORES TORRES, L. E., "Aspectos laborales de la reversión de contratas y concesiones administrativas: el impacto de las leyes 3/2017 y 9/2017 (I y II)”, Trabajo y Derecho, 42 y 43/44, 2018, p. 111 y bibliografía allí citada; más reciente, vid. GORELLI HERNÁNDEZ, J. "La reversión por la administración de las contratas: perspectiva del derecho del trabajo", Gestión y análisis de políticas públicas, 21,2019, pp. 48 y ss. o, del mismo autor, "El difícil encaje entre el ordenamiento laboral y administrativo: la subrogación de trabajadores en caso de reversión de servicios públicos”, Trabajo y Derecho, 54, 2019, p. $8 / 28$ en smarteca.
} 
como mérito muy relevante la anterior prestación de servicios. Con todo, seguramente, la solución venga marcada por la interpretación "esperable" del TJUE en la materia caso de planteársele esta cuestión, vistas las posturas mantenidas en otros asuntos. En fin, la sentencia contiene otro aspecto, relacionado con los hechos probados, aún más criticable o cuanto menos algo sorprendente: a pesar de que en los mismos figura que se aportaban en exclusiva por SEAGA, como al TS no le consta tal aportación ni su relevancia, afirma la aplicabilidad del criterio de la asunción de plantilla.

c) En fin, antes de cerrar este apartado, debe efectuarse una pequeña referencia a las llamadas subrogaciones convencionales. Sin perjuicio de que luego volveré sobre ellas desde la perspectiva de los efectos, no debe olvidarse que en aquellos casos en los que no ha habido transmisión de elementos patrimoniales en sentido amplio, ni tampoco resulta aplicable el criterio de sucesión en la plantilla, cabe que se produzca un fenómeno transmisorio por efecto de las previsiones convencionales, algo bastante frecuente al hilo de la sucesión de contratas. Pues bien, en este terreno, el criterio clásico forjado por la jurisprudencia es el relativo a la necesidad de estar en el ámbito de aplicación del convenio colectivo para que la previsión resulte aplicable. En todo caso, se trata de una materia en la que tanto la admisibilidad de la cláusula, como su obligatoriedad y alcance depende de que estemos ante un convenio de empresa o sectorial y que resulte aplicable o no a la entrante, a la saliente o a ambas $^{15}$. Aún así, la idea esencial (necesidad de que el convenio colectivo sea aplicable para que opere la cláusula subrogatoria) constituye un principio general con todos los matices que luego se puedan introducir. Por ello, resulta un tanto llamativa la STS de 26 de noviembre de 2018, rec. 2128/2016.

Un gimnasio había externalizado las labores de limpieza y con posterioridad procede a su reversión. El convenio colectivo de limpieza de la provincia donde radicaba el centro preveía la subrogación para los casos de cambio de contratista, incluso en los casos de reversión; el convenio colectivo estatal de instalaciones deportivas y gimnasios también. A pesar de ello, el gimnasio en cuestión, al recuperar la actividad, no se subroga en las relaciones laborales de los trabajadores que venían desarrollando el servicio. Así las cosas, llegada la cuestión ante el TS este entiende que no procede la subrogación convencional, confirmando una sentencia de la sala de la Comunidad Valenciana que había sostenido lo mismo.

Y es que, a su juicio, no resulta aplicable el convenio de limpieza, ni, por tanto, la previsión de subrogación convencional recogida en el mismo, pues el gimnasio no es una empresa de limpieza; por otro lado, siempre según el TS, la limpieza no está incluida en el ámbito del convenio de instalaciones deportivas y gimnasios, por lo que tampoco la previsión de este último convenio resultaba aplicable. Precisamente, este último aserto es el que entiendo que resulta más discutible. En este sentido, debe tenerse en cuenta que el convenio colectivo de instalaciones deportivas y gimnasios, al delimitar su ámbito de aplicación, alude a las actividades que se desarrollan en el interior de tales establecimientos; y que la propia clasificación profesional del convenio colectivo incluye al personal de limpieza. Así pues, la cláusula subrogatoria resultaría vinculante para el gimnasio ya que constaba en un convenio que le resultaba aplicable; otras cosa sería para los trabajadores de la empresa de limpieza afectados, a quienes la cláusula no vincularía al estar fuera del ámbito de aplicación del convenio de instalaciones deportivas, siendo para ellos la subrogación voluntaria ${ }^{16}$. Con todo, el asunto resulta dudoso por los propios términos de la cláusula convencional.

4.2. En fin, a partir de ahí, si descendemos al tratamiento de los supuestos específicos, los más relevantes se relacionan precisamente con el fenómeno de la sucesión de contratas y con el de reversión de servicios.

\footnotetext{
${ }^{15}$ El conjunto de posibilidades puede verse en NORES TORRES, L. E., La aplicación de las previsiones sobre transmisión de empresas en el ámbito de las contratas, Valencia, Tirant lo Blanch, 2012, pp. 58 y ss.

${ }^{16}$ NORES TORRES, L. E., La aplicación de las previsiones..., op. cit., p. 94.
} 
a) Por lo que respecta a los relacionados con la sucesión de contratas, tal y como he apenas recordado, la doctrina tradicional indica que estos fenómenos de por sí no implican una sucesión, salvo que puedan aplicarse los criterios tradicionales en la materia: que la sucesión vaya acompañada de la transmisión de los elementos patrimoniales necesarios para continuar con la explotación, entendidos en un sentido amplio; o que, estando ante una contrata desmaterializada, resulte aplicable el criterio de la asunción de plantilla; o que la obligación derive de un convenio colectivo aplicable. Si nos situamos en el primer supuesto -transmisión de los elementos patrimoniales-, el requisito se entiende concurrente, incluso, cuando la empresa saliente no era la titular de los medios empleados. La idea, para nada novedosa, es la que se maneja en diferentes pronunciamientos dictados al hilo del cambio de titular de un determinado contrato de gestión pública, en concreto, una guardería y ludoteca infantil por parte de unas entidades públicas.

— En efecto, las SsTS de 16 de abril de 2018, rec. 2392/2016, de 9 de mayo de 2018, rec. 3537/2016, de 29 de mayo de 2018, rec. 4050/2016, de 28 de junio de 2018, rec. 1379/2016, de 9 de enero de 2019, rec. 1889/2017 y de 29 de enero de 2019, rec. 4000/2016, se mueven en esta línea: los elementos patrimoniales habían sido aportados por la administración correspondiente, resultando por lo demás indiferente que la subrogación no constase en el pliego ni en el convenio aplicable

— En realidad, las dos últimas sentencias citadas (SsTS de 9 de enero de 2019, rec. 1889/2017 y de 29 de enero de 2019, rec. 4000/2016) no entran en el fondo por falta de contradicción, si bien son interesantes por cuanto dan noticia de un problema planteado en la instancia como es el relativo a qué sucede si los trabajadores afectados no cuentan con la titulación, algo a lo que se responde afirmando, en todo caso, la existencia de subrogación, correspondiendo a la empresa entrante la asunción del coste de la eventual extinción del contrato de aquellos sujetos que careciesen de los requisitos para desarrollar la actividad.

b) El segundo grupo se relaciona con la reversión de contratas públicas. En este punto, nuevamente resultan de aplicación los mismos criterios generales que en el terreno de la sucesión de contratas: de entrada, hay sucesión cuando se transmiten los elementos patrimoniales necesarios para seguir la actividad, incluso cuando en el pasado pertenecieron al ente; en segundo lugar, cuando tratándose de una actividad desmaterializada, proceda aplicar el criterio de la sucesión de plantilla, bien que con matices, pues, en principio, de conformidad con el art. 308 LCSP la administración no puede asumir "voluntariamente" la plantilla del predecesor ${ }^{17}$; finalmente, cuando estuviésemos ante un supuesto de sucesión convencional.

Aquí la principal duda que suele surgir es la relativa a que los servicios, en muchas ocasiones, se desarrollan sobre y/o con elementos pertenecientes al propio organismo que los descentralizó y que ahora pretende su recuperación. Así las cosas, se podrían llegar a desdibujar la concurrencia de los presupuestos aplicativos del art. 44 ET y a partir de ahí pensar que la reversión, en tales casos, constituye únicamente un mero supuesto de sucesión de actividad y no una verdadera transmisión de empresa. En este sentido, entiendo que resulta preciso diferenciar los casos en los que los bienes cedidos por la Administración resultan ser el propio objeto de los servicios de los supuestos en los que aquéllos actúan como elemento necesario de su prestación; o, en otras palabras, la frontera divisoria entre lo excluido y lo incluido en los casos en que la administración ha proporcionado los bienes estribaría en que éstos sean un sujeto "paciente" del servicio encomendado o, diversamente, actúen como "agente"18.

${ }^{17}$ GOERLICH PESET, J. Ma; NORES TORRES, L. E., “Aspectos laborales...”, op. cit., pp. 111-112; GORELLI HERNÁNDEZ, J., "El difícil encaje...", p. 8/28 en smarteca.

${ }^{18}$ GOERLICH PESET, J. Ma; NORES TORRES, L. E., “Aspectos laborales...”, op. cit., pp. 109-110; asimismo, vid. YAGÜE BLANCO, S., "Reversión de contratas públicas. Divergencias interpretativas en la identificación de las circunstancias de hecho relevantes para apreciar la sucesión de empresa”, Trabajo y Derecho, 40, p. 87. 
Pues bien, superando dudas pasadas, en este sentido se mueven distintas sentencias que analizan la reversión del servicio de restauración colectiva del Ministerio de Defensa (SsTS de 20 de abril de 2018, rec. 2764/2016, de 5 de junio de 2018, rec. 2641/2016, de 18 de julio de 2018, rec. $2720 / 2016$ o de 10 de octubre de 2018, rec. 2767/2016) o de un comedor infantil por una entidad local (STS de 26 de marzo de 2019, rec. 1916/2017). En todas ellas, la reversión del servicio acompańada de la transmisión (mejor dicho, la recuperación) de los elementos patrimoniales conduce a entender que hay una sucesión sujeta al art. $44 \mathrm{ET}$.

Ciertamente, ello no constituye novedad alguna, pues el Tribunal Supremo ya se había pronunciado en esta línea con anterioridad. No obstante, sí que existe en la materia un pronunciamiento muy relevante, si bien no procede del TS, sino del TJUE. Me refiero a la STJUE de 13 de junio de 2019 (asunto C-317/18, Correia Moreira), en la que, al hilo de la tensión entre el principio de estabilidad en el empleo derivado de la Directiva 2001/23 y los principios constitucionales de acceso al empleo público claramente se decanta por la prevalencia del primero, afirmando que el art. 2 de la misma "debe interpretarse en el sentido de que se opone a una normativa nacional que exige que, en caso de transmisión a efectos de dicha Directiva, al ser el cesionario un ayuntamiento, los trabajadores afectados, por un lado, se sometan a un procedimiento público de selección y, por otro, queden obligados por un nuevo vínculo con el cesionario".

\section{Subrogación convencional y solidaridad}

5. El segundo bloque de sentencias al que me quería referir aborda los efectos de la llamada subrogación convencional en los casos de sucesión de contratas, en concreto, la cuestión relativa a si el convenio colectivo puede limitar tales efectos a la mera subrogación y prescindir de la responsabilidad solidaria recogida en el art. 44 ET para los casos de transmisión de empresas o si, por el contrario, esta última consecuencia resulta obligada.

5.1. En este punto, hay que recordar que el TS se había posicionado en el año 2016 en el primer sentido, esto es, el de admitir la posibilidad de que el convenio colectivo, al imponer la subrogación en los casos de cambio de contratista, excluyese la responsabilidad solidaria del cesionario ${ }^{19}$, lo que originó diferentes críticas doctrinales al respecto ${ }^{20}$.

Los argumentos empleados en ese momento para ello fueron los siguientes. De entrada, según se indicaba en las sentencias citadas, no nos encontraríamos ante una sucesión de empresas de las reguladas en el art. $44 \mathrm{ET}$, pues ni habría habido una transmisión de los elementos patrimoniales que permitiesen la continuidad de la actividad, ni se habría producido una asunción voluntaria de la plantilla, sino que estaríamos ante una subrogación producida por imposición convencional. A partir de ahí, en segundo lugar, las sentencias en cuestión se encargaban de recordar que este tipo de cláusulas convencionales eran perfectamente lícitas o, en otras palabras, que el convenio colectivo constituiría un instrumento hábil para establecer este tipo de previsiones, así como que, en tales

\footnotetext{
${ }^{19}$ Así, las SsTS de 7 de abril de 2016, rec. 2269/2014 y 3 de mayo de 2016, rec. 3165/2014, en relación con el convenio de seguridad, y de 10 de mayo de 2016, rec. 2957/2014, y de 1 de junio de 2016, rec. 460/2014, en relación con el convenio de limpieza

${ }^{20}$ Así, por ejemplo, DE LA PUEBLA PINILLA, A., "Subrogación convencional y sucesión legal de empresas", Revista Galega de Dereito Social, 2, 2016, pp. 108 y ss.; MIÑARRO YANINI, M., "Contratas, subrogación convencional y exención de responsabilidad: ¿vuelve a retar la jurisprudencia nacional a la comunitaria? Comentario a la STS de 10 de mayo de 2016, RCUD 2957/2014”, Revista de Trabajo y Seguridad Social. CEF, 403, 2016, pp. 161 y ss.; ARAGÓN GÓMEZ, C., "Régimen jurídico aplicable a la sucesión de plantilla que opera por imperativo convencional", Trabajo y Derecho, 25, 2017, pp. 74 y ss.; en sentido diverso, compartiendo el criterio jurisprudencial, NORES TORRES, L. E., "Sucesión de contratas y subrogación convencional: el impulso a una doctrina acertada (a propósito de la STS de 7 de abril de 2016), Información Laboral, 9, 2016, pp. 151 y ss.
} 
casos, los efectos derivados deberían ser los previstos en el convenio colectivo de que se tratase, tal y como se habría sostenido en otros pronunciamientos anteriores que las propias sentencias citaban. En tercer lugar, continuaban razonando estos pronunciamientos, nada de ello supondría una vulneración del texto estatutario, ni de la Directiva 2001/23/UE, ni de la STJUE de 24 de enero de 2002 (asunto C-51/00, TEMCO), pues estaríamos en un terreno en el que la relación entre las normas se produciría en términos de suplementariedad o concurrencia no conflictiva. En fin, por lo demás, las sentencias referidas subrayaban que aquella solución resultaba coherente con el tratamiento que había dispensado el propio tribunal a otro tipo de cláusulas convencionales en las que se recogían otras subrogaciones «limitadas», exigiendo que los trabajadores tuviesen una determinada antigüedad en la empresa, y respecto las cuales no se habría nunca cuestionado su licitud.

Esta orientación se siguió en muchos pronunciamientos posteriores ${ }^{21}$. Y esa misma continuidad se aprecia también durante la primera mitad de 2018: SsTS de 10 de abril de 2018, rec. 3684/2016, de 3 de mayo de 2018, rec. 2346/2016, de 9 de mayo de 2018, rec. 3065/2016, de 29 de mayo de 2018, recs. 2481/2016 y 2748/2016, de 31 de mayo de 2018, rec. 2586/2016.

5.2. Pues bien, en ese contexto se dicta la STJUE de 1 de julio de 2018 (asunto C-60/17, Somoza Hermo) resolviendo una cuestión prejudicial elevada por el TSJ de Galicia relacionada con esta materia. En efecto, al hilo de la sucesión en la contrata de seguridad del Museo de las Peregrinaciones de Santiago de Compostela, en la que se produce una subrogación del personal por obra del convenio colectivo, la Sala de Galicia pregunta dos cosas: por un lado, si la subrogación convencional se puede reconducir al art. 1.1 de la Directiva; por otro lado, si un Estado haciendo uso del art. 3.1 de la Directiva (posibilidad de que los estados miembros impongan la solidaridad) ha previsto la solidaridad, resulta conforme con dicho precepto una interpretación que sostenga que tal responsabilidad no se aplica cuando la asunción de plantilla viene impuesta por el convenio colectivo y en el convenio no se recoge.

a) La sentencia literalmente indicó, en primer lugar, que "El artículo 1, apartado 1, de la Directiva 2001/23/CE del Consejo, de 12 de marzo de 2001, sobre la aproximación de las legislaciones de los Estados miembros relativas al mantenimiento de los derechos de los trabajadores en caso de [transmisiones] de empresas, de centros de actividad o de partes de empresas o de centros de actividad, debe interpretarse en el sentido de que esta Directiva se aplica a una situación en la que un arrendatario de servicios ha resuelto el contrato de prestación de servicios de vigilancia de instalaciones celebrado con una empresa y, a efectos de la ejecución de la prestación, ha celebrado un nuevo contrato con otra empresa que se hace cargo, en virtud de un convenio colectivo, de una parte esencial, en términos de número y de competencias, del personal que la primera empresa destinaba a la ejecución de dicha prestación, siempre y cuando la operación vaya acompañada de la transmisión de una entidad económica entre las dos empresas afectadas"; en segundo lugar, que "El Tribunal de Justicia de la Unión Europea no es competente para responder a la segunda cuestión prejudicial planteada por el Tribunal Superior de Justicia de Galicia, mediante resolución de 30 de diciembre de 2016".

Así pues, la cuestión de la solidaridad, a mi juicio, se remitía a un problema estrictamente de relación entre el art. 44 ET y el convenio colectivo, pero no de ajuste de las previsiones convencionales a las previsiones recogidas en la normativa comunitaria.

b) A pesar de ello, con base en esta sentencia, el TS ha cambiado el criterio que venía sosteniendo desde 2016 en esta materia y ha pasado a entender que, en el caso de subrogaciones convencionales operadas en supuestos de contratas que se consideran desmaterializadas, la contratación del personal de la empresa saliente, aunque no se produzca de un modo libre, sino que venga impuesta

${ }^{21}$ Entre otras, SsTS de 6 de julio de 2017, recs. 1550/2016 y 1669/2017; STS de 25 de julio de 2017, rec. 2239/2017 
por el convenio colectivo aplicable, lleva a la aplicación del criterio de sucesión de plantilla, así como a que la subrogación convencional se convierta en una suerte de subrogación legal y, por tanto, se aplique el art. $44 \mathrm{ET}$ en su integridad, incluido el mecanismo de la responsabilidad solidaria ${ }^{22}$. El cambio de criterio se produce con la STS de 27 de septiembre de 2018, rec. 2747/2016, dictada por Sala General, a la que después han seguido otras, como las SsTS de 24 y 25 de octubre de 2018, recs. $2842 / 2016$ y $4007 / 2016$.

6. En fin, no querría cerrar este apartado sin efectuar un par de consideraciones críticas relacionadas con el cambio de criterio, tanto en cuanto a la oportunidad, como a sus consecuencias:

6.1. La primera es que, a mi juicio, el cambio de criterio no resultaba necesario o, mejor dicho, no era una consecuencia que derivase de manera obligada de la STJUE, sino que es un problema exclusivo de relación entre el art. 44 ET y el convenio colectivo, según se encarga expresamente de indicar el TJUE, tanto en el razonamiento como en el fallo. De hecho, como ya he sostenido en otro lugar, sigo pensando que el convenio colectivo, en supuestos que no constituyen una transmisión verdadera, puede imponer la subrogación y prescindir de la solidaridad, pues una previsión convencional de tal tipo respetaría tanto la Directiva como del art. 44 ET; a los argumentos que en su día señalara el TS se pueden añadir ahora los derivados de la jurisprudencia comunitaria reciente en materia de vacaciones ${ }^{23}$. Al hilo de ello, también me sorprende la facilidad con que el TS ha cambiado de postura: con todo lo que le costó admitir, por ejemplo, la incorporación de la doctrina sobre la sucesión de plantilla, o lo discutida que fue la propia sentencia de 2016, aquí se ha mostrado muy dúctil; de hecho, el voto particular no cuestiona la opinión mayoritaria, sino tan solo su aplicación al caso concreto, pues no constaba en los hechos probados que la empresa entrante hubiese asumido una parte importante de la plantilla.

6.2. La segunda consideración a efectuar enlaza con algo que ya estaba presente en la STS de 7 de abril de 2016 y en los estudios doctrinales sobre sucesión de contratas más clásicos ${ }^{24}$ : la aplicación del criterio de sucesión de la plantilla en las subrogaciones convencionales y su conversión en una subrogación de tipo "legal" (en el sentido de reconducible al art. 44 ET) obligaría a considerar la ilegalidad de las cláusulas convencionales que exigen una determinada antigüedad o el cumplimiento de obligaciones informativas para que esta resulte operativa. Y todo ello al margen de la lectura que pueda tener en términos de consecuencias futuras para este tipo de cláusulas, ya que su mantenimiento en la "agenda" negocial se presenta cuanto menos como "dudosa", según ha destacado la doctrina ${ }^{25}$.

${ }^{22}$ Sobre los efectos derivados del cambio de doctrina, vid. DE LA PUEBLA PINILLA, A., "Efectos de la rectificación de la doctrina sobre la subrogación convencional. Reflexiones a partir de la STS de 27 de septiembre de 2018", Trabajo y Derecho, 48, 2018, pp. 108 y ss.

${ }^{23}$ En efecto, ya cerrado este estudio, la STJUE de 19 de noviembre de 2019, asuntos C-609/17 y C.610/17, ha señalado que, en relación con los días de vacaciones previstos en un convenio colectivo que mejora las previsiones comunitarias en materia de duración de las vacaciones, el hecho de que los días "adicionales" que superen el mínimo no puedan aplazarse por coincidir con una enfermedad, no contraviene la Directiva 2003/88).

${ }^{24}$ Entre otros, CABEZA PEREIRO, J., "La subrogación empresarial en las contratas de limpieza sí se ampara en la Directiva 23/2001/CE", Actualidad Laboral, 21, 2002, p. 1101; GARCÍA ROMERO, B., "Ámbito de aplicación de la Directiva 2001/23/ CE, noción de traspaso y negociación colectiva (estado de la cuestión tras la STJUE de 24 de enero de 2002, asunto Temco", Revista de Derecho Social, 18, p. 143; MORENO GENÉ, J., El nuevo régimen..., op. cit., p. 75); SANGUINETI RAYMOND, W., "Las cláusulas de subrogación convencional frente a los vaivanes jurisprudenciales" en ESCUDERO RODRÍGUEZ, E. (Coord.), La negociación colectiva en España: una mirada crítica, Valencia, Tirant lo Blanch, 2006, pp. 111-112.

${ }^{25}$ DE LA PUEBLA PINILLA, A., "Efectos de la rectificación...", op. cit., p. 114. 


\section{El plazo de tres años para exigir la responsabilidad}

7. Un tercer bloque de pronunciamientos dictados en el período analizado aborda la cuestión del significado del plazo de tres ańos establecido en el art. 44.3 ET para exigir la responsabilidad solidaria respecto las obligaciones nacidas con anterioridad a la transmisión y, de manera concreta, su naturaleza, así como su carácter autónomo o no respecto el plazo del art. 59 ET. En definitiva, estas sentencias tratan de determinar si el plazo referido opera o no como un plazo singular de prescripción, de manera que en los supuestos de transmisión de empresa por actos inter vivos las deudas previas están sometidas o no al plazo general de un año del art. 59 ET.

7.1. La cuestión, así planteada, es muy similar a la que se suscita al hilo de los plazos de uno y tres años que fija el art. 42 ET para exigir la responsabilidad solidaria del empresario principal respecto las obligaciones salariales y de seguridad social nacidas durante la vigencia de la contrata a contar tras la finalización de la misma. En este punto, tradicionalmente se han barajado dos grandes interpretaciones ${ }^{26}$. Por un lado, que estamos ante una reiteración respecto lo establecido en el art. 59 ET. Así, el plazo general de un año previsto en el art. 59 ET regiría también aquí, eso sí, en la medida en que la acción no hubiese prescrito con anterioridad; es decir, se trataría de una previsión absolutamente superflua. Por otro lado, la segunda opción pasaría por entender que estamos ante un plazo que presenta un carácter autónomo: el empresario principal responde de las deudas pendientes durante el ańo siguiente a la terminación de la contrata, lo cual no tienen mucho sentido, pues tendría una mayor perdurabilidad en el tiempo la responsabilidad del principal que la del contratista.

Alguna sentencia dictada en suplicación, tras recoger ambas interpretaciones, se había decantado de manera rotunda por la primera opción: "al establecer el art. 42 que la obligación del empresario comitente es exigible durante el año siguiente a la terminación de su encargo, parece que admite la posibilidad de exigir deudas salariales del contratista que ya estuvieran prescritas antes de la finalización de la contrata, pues, en otro caso no sería más que una reiteración indeseada de lo preceptuado en el art. 59 del E.T. Como ello supondría imponer una obligación más intensa al empresario principal que al contratista empleador directo del trabajador, debe ser rechazada equiparando ambas responsabilidades en el tiempo en que pueden ser exigidas" ${ }^{27}$.

A mi juicio, los términos del debate se han movido por unos senderos un tanto erróneos. Aunque la idea de partida sobre que la "responsabilidad" del empresario principal se extiende durante el ańo siguiente a la finalización de la contrata, eso sí, en la medida en que las "acciones" no estén prescritas resulta acertada, parece imprescindible insistir en una cosa: la necesidad de diferenciar entre el plazo de ejercicio de la acción (el año al que alude el art. 59 ET a contar desde el momento en que la misma pudo ejercitarse) y el plazo durante el cual es exigible la responsabilidad del empresario principal (el año al que alude el art. 42 ET tras la finalización de la contrata). Así, el trabajador, durante la vigencia de la contrata, podrá dirigirse indistintamente contra cualquiera de los deudores solidarios, eso sí, en la medida en que la "acción" no haya prescrito. Una vez finalice la contrata, si las acciones no se entablan contra el principal y solo se dirigen contra el contratista, las eventuales interrupciones solo operan respecto el contratista, y cuando haya pasado un año, la responsabilidad del principal habrá desaparecido: y ello, seguramente, porque la naturaleza de esta responsabilidad no sea exactamente una verdadera solidaridad, sino una suerte de fianza solidaria. La doctrina de suplicación ya había manejado una lectura de este tipo ${ }^{28}$. Y esta es también la orientación que, en

\footnotetext{
${ }^{26} \mathrm{Al}$ respecto, vid. MONTOYA MEDINA, D., Trabajo en contratas..., op. cit., p. 234.

${ }^{27}$ STSJ Cataluña de 15 de enero de 2010, rec. 6474/2008.

${ }^{28}$ Así, la STSJ Castilla-León Burgos de 16 de febrero de 2012, rec. 7/2012. Asimismo, la STSJ Galicia de 15 de marzo de 2010, rec. 1617/2006, afirmaba "Existe una relevante matización en cuanto a ese plazo anual al que se refiere el artículo 42 del ET, y es el hecho
} 
cierto modo, sigue la STS de 5 de diciembre de 2017, rec. 2664/2015. En efecto, tras recordar el distinto origen que tienen las obligaciones del contratista y las responsabilidades del principal, esta sentencia configura esta última como una solidaridad impropia: "la responsabilidad solidaria de la empresa principal la impone el art. 42-2 del ET diferenciándola en su nacimiento, duración y exigencia de la de pago de salarios que regulan los artículos 1, 26, 29 y 59 del ET en sus distintos particulares, lo que hace que no sea una obligación solidaria de las que el articulo 1137 del Código Civil contempla y que tenga un régimen en orden a la prescripción de esa responsabilidad diferente y al que resulta inaplicable el art. 1974 del Código Civil en orden a la interrupción de la prescripción por la reclamación a otro, como ya apuntó esta Sala, aunque fuese como "obiter dicta" en su sentencia de 20-9-2007 (R. 3539/2005 )".

7.2. Pues bien, esta misma orientación es la que subyace en las sentencias del Tribunal Supremo más recientes que han abordado esta cuestión. En efecto, la STS de 17 de abril de 2018, rec. 78/2016, una vez recordado el contenido de los arts. 59 ET, 44.3 ET, 1969 Cc y 44.1 ET, y tras resaltar la conexión que tienen los referidos preceptos estatutarios con los de la Directiva comunitaria, expresamente ha señalado que: "el art. 44.3 ET no establece plazo de prescripción singular y diverso al general de un año previsto en el art. 59 ET, sino que sólo delimita temporalmente la responsabilidad solidaria que se establece entre el cesionario y el cedente, fijando al respecto un plazo de actuación-caducidad-de tres años para el ejercicio de aquella acción-necesariamente viva-que el trabajador pudiera ostentar frente al empresario transmitente". A ello añade: "la previsión que contiene el art. 44.3 ET tiene un alcance claro, cual es que la subrogación en las deudas salariales se produce en los términos propios de tal figura jurídica, precisando que la responsabilidad solidaria que el precepto dispone para el adquirente -por las deudas previas a su condición empresarial novedosamente adquirida- unicamente le puede ser exigida durante los tres años posteriores a la sucesión, de manera que ejercicio de la acción por el trabajador frente a ese empresario sucesor, reclamando aquellos débitos anteriores, únicamente es factible durante esos tres primeros años. y ello aunque transcurrido ese plazo la correspondiente acción persista viva por haberse interrumpido su decadencia mediante cualquiera de los medios que el derecho admite [art. 1973 CC J". Con posterioridad, las SsTS de 11 de julio de 2018, rec. 916/2017, de 10 de enero de 2019, rec. 925/2017 y de 28 de febrero de 2019, rec. 777/2017 han seguido la misma doctrina. Una cuestión que no resuelven estas sentencias es la relativa al tratamiento de las causas interruptivas respecto la responsabilidad solidaria. Al respecto, remite a las afirmaciones que sostuvo en la STS de 5 de diciembre de 2017, rec. 2664/2015, si bien esta sentencia, como se acaba de recordar, se dictó en un litigio relacionado con la aplicación del art. 42 ET y no del art. 44 ET; en todo caso, anuncia un análisis más profundo de la cuestión para el futuro. Por lo demás, la remisión a la sentencia de 2017 implicaría que las reclamaciones dirigidas contra el deudor principal, o los reconocimientos de deuda por este efectuados, no desplegarán efectos interruptivos respecto el deudor solidario. En el ámbito del art. 42 ET, una vez finalizada la contrata, la responsabilidad del deudor solidario solo podrá plantearse durante 1/3 años y en la medida en que la acción esté vigente. Y esto es trasladable en líneas generales al terreno del art. 44 ET, si bien la propia dinámica de este precepto introduce modificaciones (de hecho, lo simplifica): en el ámbito del art. 44 ET, la responsabilidad del deudor

\footnotetext{
de que solo cabe exigir responsabilidad del empresario principal, durante el año siguiente a la terminación del encargo, a fin de no perpetuar en el tiempo su relación con la contrata impidiéndole ya no desvincularse de un encargo ya terminado, sino de situarse al margen de las múltiples y variadas reclamaciones, que por distintos incumplimientos por parte de la empresa contratista o subcontratista, pudieran tener lugar en el futuro. Y en aplicación de este plazo, la acción ejercitada contra la recurrente se encuentra prescrita, porque la norma especifica que regula la cuestión, como acabamos de indicar, se contiene en el artículo 42 del ET, sin poderse aplicar, en este caso, el mecanismo interruptivo previsto en el artículo 1974 del Código Civil. Terminada la contrata para el actor, en la fecha en la que fue despedido esto es, 2 de noviembre de 2004, la recurrente solo podria responder solidariamente de las deudas salariales que pesan sobre la empresa codemandada y subcontratista, si se hubiera respetado el plazo de un año y no presentándose la demanda contra la empresa principal hasta el 22 de noviembre de 2005, el recurso de suplicación formulado prospera, con la consecuente revocación parcial de la sentencia de instancia".
} 
solidario no surge al mismo momento que la deuda como en cambio sucede en el espacio cubierto por el art. $42 \mathrm{ET}$, sino al tiempo de la transmisión; y en la medida que en ese momento la deuda esté vigente. A partir de la transmisión, se responde durante tres años; si en ese período no se le requiere (las acciones solo se entablan contra el principal), transcurrido el mismo, no responde.

\section{Subrogación y reducción de contrata}

8. Además de la responsabilidad solidaria, la otra consecuencia esencial que se deriva de los fenómenos transmisorios es la relativo a la subrogación del personal con las mismas condiciones que viniesen disfrutando en la empresa de origen. Al margen de la STS de 25 de abril de 2019, rec. 770/2017, en la que se recuerda el alcance "general" de la obligación de mantener tales condiciones (en concreto, unos billetes de avión, siguiendo una línea muy consolidada ${ }^{29}$ ), llama la atención un cuarto bloque de sentencias que, en el marco de las sucesiones de contratas susceptibles de ser consideradas como un supuesto de transmisión de empresa, abordan la polémica cuestión de las consecuencias que tiene la reducción de una contrata.

8.1. La postura clásica sobre el particular ha sido la de entender que si la sucesión de contratas constituye un supuesto de transmisión, el contratista entrante asume la totalidad de la mano de obra, sin perjuicio de que puede llevar a cabo un despido objetivo respecto el personal sobrante, abonando la correspondiente indemnización. Ello será así, se matiza, salvo que el convenio colectivo disponga otra cosa. Pues bien, sucede que el convenio de seguridad prevé algo diverso. El principio general es la existencia de subrogación: si la reducción es superior a doce meses, le corresponde a la saliente quedarse con la mano de obra (y proceder en su caso a un despido objetivo); ahora bien, si la reducción es por tiempo inferior a doce meses o se produce una ampliación, operará la subrogación de la empresa entrante.

A ello se refieren las SsTS de 8 de mayo de 2018, rec. 3484/2016, de 17 de julio de 2018, rec. $2834 / 2016$ y de 30 de octubre de 2018, rec. 3767/2016. En todas ellas, hay una contrata de seguridad suscrita con Prosegur que no se renueva; la nueva contratista es Securitas, pero con una contrata reducida. Así las cosas, Securitas se subroga solo parcialmente y los trabajadores no contratados demandan por despido. Tanto en la instancia como en suplicación se entendió que había subrogación y que Securitas debía subrogarse en la totalidad de las relaciones laborales, sobre la base de que, en realidad, no había tal reducción de la contrata, sino una surte de "desdoblamiento" de la misma, separando la vigilancia de las labores de conserjería. Ahora bien, el TS entiende que la responsabilidad no es de Securitas, sino de Servicios Securitas que había ganado la contrata de conserjes-acceso.

8.2. Esta posición ha sido con posterioridad matizada, como consecuencia de la sentencia del TJUE de 1 de julio de 2018 (asunto 60/17, Somoza Hermo). Así, las SsTS de 8 de enero de 2019, rec. 2833/2016 y de 5 de marzo de 2019, rec.2892/2017, han entendido que, al haber incardinado el TJUE la subrogación convencional en el ámbito de la Directiva, la sucesión puede implicar la transmisión de una entidad organizada que mantiene su entidad en la medida en que sea aplicable el criterio de la sucesión de la plantilla y, en consecuencia, la subrogación es total, subrogándose, por tanto, Securitas en el conjunto de la mano de obra. Esta misma postura, se sostiene con unos sujetos diversos en la STS 9 de enero de 2019, rec. 108/2018.

${ }^{29}$ SsTS de 27 de septiembre de 2016, recs. 350/2015 y 882/2015, de 30 de septiembre de 2016, rec. 3980/2014, de 4 de octubre de 2016, rec. 689/2015 y de 3 de mayo de 2017, rec. 2356/2015. 


\section{Transmisión y concurso}

9. Un último bloque de pronunciamientos al que me quiero referir es el que aborda ciertos efectos de la transmisión de empresa en el seno del concurso o, mejor dicho, se trata de supuestos en los que las relaciones laborales se han extinguido con carácter previo a la adjudicación de la empresa, centro de trabajo o UPA en la fase de liquidación, arrastrando la empresa deudas previas a la liquidación respecto trabajadores que ya no están vinculados al tiempo de la adjudicación ${ }^{30}$.

En efecto, se trata de un número considerable de sentencias (STS de 27 de febrero de 2018, rec. 112/2016; STS de 26 de abril de 2018, rec. 2004/2016; STS de 5 de junio de 2018, rec. 417/2017; STS de 12 de julio de 2018, rec. 3525/2018; STS de 12 de septiembre de 2018, rec. 1549/2017; SsTS de 3 de octubre de 2018, recs. 3710/2017, 323/2017, 3664/2017 y 1733/2017; STS de 17 de octubre de 2018, rec. 2340/2017; STS de 27 de noviembre de 2018, recs. 1902/2017 y 1958/2017; STS de 23 de enero de 2019, rec. 1690/2017; STS de 11 de septiembre de 2019, rec. 1505/2019) del que podemos extraer diferentes ideas de relevancia.

9.1. La primera de ellas es la relativa al orden competente para decidir si existe transmisión o no. Pues bien, en este punto el criterio está muy consolidado, incluso en pronunciamientos anteriores $^{31}$, entendiéndose que corresponde al juez de lo social "porque en la resolución de este problema se encuentra implicada la recurrente, quien no ha sido parte en el proceso concursal, ni como deudor ni como acreedor, al haberse limitado a comprar una unidad productiva de la empresa concursada." Y es que, el hecho de que el juez del concurso al adjudicar la unidad productiva indique que no hay sucesión de empresa, constituye una declaración de carácter prejudicial en los términos del art 9 LC que no despliega efectos fuera del concurso.

9.2. La segunda idea relevante que se extrae de este bloque de sentencias es la relativa a que la adjudicación de una unidad productiva constituye una sucesión de empresa, obviamente, si se dan los requisitos para ello. La lectura conjunta de los arts. 148 y 149 conduce a ello, de manera singular el 148.4 LC, ya que "la norma no ha excluido que la adquisición de una unidad productiva en el seno del concurso suponga sucesión de empresa sino, al contrario, de forma indirecta está admitiendo que en dicho supuesto se produce sucesión de empresa, al remitir al articulo 64 LC los supuestos en los que las operaciones previstas en el plan de liquidación implicasen modificaciones sustanciales colectivas, traslados colectivos, suspensiones o extinciones colectivas de contratos; porque si la adquisición de una unidad productiva autónoma en el seno del concurso no supusiera que existe sucesión de empresa, la remisión del art. 148.4 LC al procedimiento descrito en el art. 64 LC, sería superflua, ya que la adquisición de la unidad productiva autónoma no conllevaría la asunción de los trabajadores de la empleadora, por lo que el plan de liquidación habría de limitarse a contemplar las condiciones de la realización de bienes y derechos del concursado, pero sin previsión alguna respecto a la situación de los trabajadores. Si del precepto resultare que no hay sucesión de empresa sería única y exclusivamente la empleadora la responsable de adoptar las medidas legales para la modificación sustancial de condiciones de trabajo, extinciones colectivas... de sus trabajadores, pero estas medidas no tendrian que aparecer ligadas a la aprobación del plan de liquidación de los bienes de la masa activa ya que la adquirente sería por completo ajena a la suerte de los trabajadores de la empleadora".

\footnotetext{
${ }^{30} \mathrm{Al}$ respecto, vid. in extenso ALTÉS TÁRREGA, J. A., "La sucesión de empresa en la fase de liquidación concursal: divergencias interpretativas y la necesaria unificación de criterios”, Derecho de las Relaciones Laborales, 10, 2018, pp. 1096 y ss.

${ }^{31}$ SsTS11 de enero de 2018, rec. 3290/2015, de 5 de julio de 2017, rec. 563/2015, de 18 de mayo de 2017, rec. 1645/2015, de 11 de enero de 2017, rec. 1689/2015.
} 
9.3. En tercer lugar, debe destacarse que la responsabilidad también alcanza a las deudas pendientes con los trabajadores cuyo contrato ya se había extinguido con anterioridad a la adjudicación, algo que ya se sostiene desde antiguo ${ }^{32}$. Un argumento adicional para sostener esta postura ha sido el de la separación entre la consecuencia relativa al mantenimiento de las relaciones laborales y la subrogación con las mismas obligaciones y derechos (art. 44.1 ET) y la responsabilidad solidaria (art. $44.3 \mathrm{ET})$.

9.4. Finalmente, hay que subrayar el carácter limitado que, a estos efectos, tienen los arts. 146.bis y 149.4 LC, en el sentido de que el margen de exoneración con que cuenta el juez del concurso es limitado: la parte de la cuantía de los salarios o indemnizaciones pendientes de pago anteriores a la enajenación que sea asumida por el FOGASA.

\section{Algunas consideraciones finales y propuestas}

10. Una sensación que surge a menudo tras la lectura de los diversos pronunciamientos jurisprudenciales que van apareciendo tanto en esta materia como en otras es la relativa a que las instituciones laborales resultan cada vez mas difíciles de entender, de manera especial aquellas en las que incide el Derecho Comunitario. En el caso de la transmisión de empresa, las dudas se acrecientan por el más que seguro distanciamiento entre la norma y la realidad normada, algo en lo que la reforma del año 2001 pudo incidir y que, por desgracia, no aprovechó, limitándose a ajustar el contenido del art. 44 ET a los mandatos derivados de la Directiva 2001/23. Sin embargo, tal y como evidencian las novedades jurisprudenciales de las que he intentado dar cuenta en este trabajo, hay una serie de puntos críticos en los que se debería incidir.

10.1. De entrada, hay una cuestión previa de gran relevancia que debería afrontarse y es la relativa a la determinación de quién es el responsable solidario, una cuestión en cuya interpretación debería efectuarse un verdadero giro copernicano en las últimas interpretaciones y recuperar otras lecturas manejadas en el pasado. En este sentido, si bien se mira, el responsable "directo" de las deudas contraídas con los trabajadores afectados por la transmisión debería entenderse que es el cesionario; en eso consiste la subrogación en derechos y obligaciones ${ }^{33}$. La solidaridad, en realidad, se impondría sobre el cedente, para asegurarse que no efectúe una transmisión hacia una empresa insolvente con el único fin de librarse de responsabilidades al respecto ${ }^{34}$. Asimismo, incluso, cabría hablar de una "bidireccionalidad" de la solidaridad, pues sobre el cesionario también pesaría una responsabilidad solidaria, pero, en este caso, respecto las deudas pendientes con los trabajadores que vieron extinguidos sus contratos con anterioridad a la transmisión ${ }^{35}$.

10.2. Un segundo punto en el que debería incidirse es el relativo a la propia naturaleza de la responsabilidad, aclarando si estamos ante una verdadera solidaridad, una solidaridad "impropia" como ha indicado el TS o una fianza solidaria; y ello por la trascendencia que tiene, entre otras cosas, respecto del cómputo de los plazos, un tema que, por lo demás, también debería ser abordado

\footnotetext{
${ }^{32}$ STS de 4 de octubre de 2003, rec. 585/2003.

${ }^{33}$ En este sentido, DE LA PUEBLA PINILLA, A., "Efectos de la rectificación...", op. cit., p. 115.

${ }^{34} \mathrm{Al}$ respecto, vid. ALTÉS TÁRREGA, J., "La responsabilidad del adquirente en la transmisión de empresa laboral: subrogación contractual y responsabilidad solidaria", Trabajo y Derecho, 50, 2019, pp. 53 y ss. y bibliografía por él citada.

${ }^{35}$ ALTÉS TÁRREGA, J. , "La responsabilidad del adquirente...”, op. cit., p. 54; YAGÜE BLANCO, S., "Entre subrogación convencional y transmisión de empresa: la sucesión de plantilla”, Trabajo y Derecho, 52, 2019, pp. 53 y ss.
} 
para marcar esa diferencia entre el plazo de ejercicio de las acciones y el plazo de exigibilidad de la responsabilidad.

10.3. El tercer aspecto sobre el que merece la pena reflexionar afecta a la subrogación convencional. $Y$ es que las últimas orientaciones interpretativas que impiden en las contratas desmaterializadas imponer la subrogación con exclusión de la solidaridad podrían suponer un "serio obstáculo" 36 o una suerte de "sentencia de muerte" para este tipo de previsiones convencionales. Ciertamente, la misma lectura se efectuaba del criterio de la asunción de plantilla o de la doctrina sentada por la sentencia TEMCO y, a pesar de ello, las previsiones negociales que imponen la subrogación han seguido existiendo, lo que lleva a pensar que los agentes sociales perseveran en su "indulto". La cuestión es compleja por las implicaciones que este tipo de cláusulas pueden tener en términos de competencia entre las empresas. En todo caso, tal y como ha evolucionado la jurisprudencia interna y comunitaria, convendría una expresa regulación en el seno del 44 ET que delimitase el papel a desarrollar por la negociación colectiva. Así, una vez el legislador ha previsto para los casos de transmisión de empresa el mantenimiento de las relaciones laborales y la subrogación (por mandato comunitario), así como la solidaridad (como decisión libre y no obligatoria en la Directiva), el precepto podría indicar que los convenios colectivos pueden fijar la obligación de subrogarse en aquellos casos en los que legalmente no sea obligatorio, así como, si lo estiman conveniente, imponer en tales supuestos la responsabilidad solidaria, algo que sería plenamente respetuoso con el Derecho Comunitario.

10.4. En fin, por último, no está de más destacar el fracaso de las previsiones normativas en materia de transmisión en el caso de empresas concursadas, pues tanto las previsiones como su interpretación no favorecen demasiado su objetivo, esto es, facilitar la posibilidad de reflotamiento de las empresas afectadas ${ }^{37}$.

\section{Bibliografía citada}

Altés TÁrrega, J. A., "La sucesión de empresa en la fase de liquidación concursal: divergencias interpretativas y la necesaria unificación de criterios", Derecho de las Relaciones Laborales, 10, 2018, pp. $1096-116$.

Altés TÁrrega, J. A., "La responsabilidad del adquirente en la transmisión de empresa laboral: subrogación contractual y responsabilidad solidaria”, Trabajo y Derecho, 50, 2019, pp. 39-60.

Aragón Gómez, C., "Régimen jurídico aplicable a la sucesión de plantilla que opera por imperativo convencional”, Trabajo y Derecho, 25, 2017, pp. 74-82.

Cabeza Pereiro, J., "La subrogación empresarial en las contratas de limpieza sí se ampara en la Directiva 23/2001/CE”, Actualidad Laboral, 14, 2002, pp. 1096-1103.

De La Puebla Pinilla, A., "Subrogación convencional y sucesión legal de empresas", Revista Galega de Dereito Social, 2, 2016, pp. 79-111.

De la Puebla Pinilla, A., "Efectos de la rectificación de la doctrina sobre la subrogación convencional. Reflexiones a partir de la STS de 27 de septiembre de 2018", Trabajo y Derecho, 48, 2018, pp. 108-118.

García Murcia, J. (Dir.), Transmisión de empresa y sucesión en el desarrollo de actividades empresariales. Un estudio a partir de la jurisprudencia del Tribunal Supremo, Cizur Menor, Thomson Reuters Aranzadi, 2019.

\footnotetext{
${ }^{36}$ DE LA PUEBLA PINILLA, A., Efectos de la rectificación...”, op. cit., p.114.

${ }^{37}$ ALTÉS TÁRREGA, J., "La sucesión de empresa...”, op. cit., pp. 1096 y ss.
} 
García Ortega, J., "La sucesión de contratistas", en BLAT GIMENO, F. et altri, Descentralización productiva y protección del trabajo en contratas. Estudios en recuerdo de Francisco Blat Gimeno, Valencia, Tirant lo Blanch, 2000, pp. 341-382.

García Romero, B., "Ámbito de aplicación de la Directiva 2001/23/CE, noción de traspaso y negociación colectiva (estadio de la cuestión de tras la STJCE de 24 de enero de 2002, asunto Temco)", Revista de Derecho Social, 18, 2002, pp. 129-143.

González Biedma. E., "Los efectos jurídico-laborales de la sustitución de empresas contratistas de servicios", Relaciones Laborales-II, 1993, pp. 240-282.

Goerlich Peset, J. Ma; Nores Torres, L. E., "Aspectos laborales de la reversión de contratas y concesiones administrativas: el impacto de las leyes 3/2017 y 92017 (I y II)" , Trabajo y Derecho, 42 y 43/44, 2018, pp. 104-113 y 102-114.

Gorelli Hernández, J., "La reversión por la administración de las contratas: perspectiva del derecho del trabajo", Gestión y análisis de politicas públicas, 21, 2019, 41-60.

Gorelli Hernández, J., "El difícil encaje entre el ordenamiento laboral y administrativo: la subrogación de trabajadores en caso de reversión de servicios públicos", Trabajo y Derecho, 54, 2019, pp. 13-32 (1 a 28 en smarteca).

Llano Sánchez, M., Responsabilidad empresarial en las contratas y subcontratas, Madrid, La Ley, 1999.

Miñarro Yanini, M., "Contratas, subrogación convencional y exención de responsabilidad: ¿vuelve a retar la jurisprudencia nacional a la comunitaria? Comentario a la STS de 10 de mayo de 2016, RCUD 2957/2014", Revista de Trabajo y Seguridad Social. CEF, 403, 2016, pp. 161-166.

Montoya Medina, D., Trabajo en contratas y protección de los trabajadores, Valencia, Tirant lo Blanch, 2004.

Moreno Gené, J., El nuevo régimen jurídico-laboral de la sucesión de empresa, Valencia, Tirant lo Blanch, 2003.

Nores Torres, L. E., La aplicación de las previsiones sobre transmisión de empresas en el ámbito de las contratas, Valencia, Tirant lo Blanch, 2012.

Nores Torres, L. E., "Sucesión de contratas y subrogación convencional: el impulso a una doctrina acertada (a propósito de la STS de 7 de abril de 2016), Información Laboral, 9, 2016, pp. 151-163.

Sala Franco, T., "La sucesión de contratas", en PEDRAJAS MORENO, A. (Dir.), La externalización de actividades laborales (outsourcing): una visión multidisciplinar, Valladolid, Lex Nova, 2002, pp. 265-286.

Sala Franco, T.; Pedrajas Moreno, A., "Los problemas laborales de la sucesión de contratas", en BLASCO PELLICER, A. (Coord.), El empresario laboral. Estudios jurídicos en homenaje al Profesor CAMPS RUIZ con motivo de su jubilación, Valencia, Tirant lo Blanch, 2010, pp. 385-412.

SANGUineti Raymond, W., "Las cláusulas de subrogación convencional frente a los vaivenes jurisprudenciales”, en ESCUDERO RODRÍGUEZ, R. (Coord.), La negociación colectiva en España: una mirada critica, Valencia, Tirant lo Blanch, 2006, pp. 99-118.

YaGüE Blanco, S., "Reversión de contratas públicas. Divergencias interpretativas en la identificación de las circunstancias de hecho relevantes para apreciar la sucesión de empresa”, Trabajo y Derecho, 40, 2018, pp. 81-92.

YaGÜE BlanCo, S., "Entre subrogación convencional y transmisión de empresa: la sucesión de plantilla”, Trabajo y Derecho, 52, 2019, pp. 37-56. 